\title{
The changing paradigms of project management
}

\author{
Julien Pollack \\ University of Technology, Sydney
}

\begin{abstract}
This paper examines the academic literature on Project Management in relation to the hard and soft paradigms, two broad tendencies for thought and action that have had considerable impact on the development of a variety of comparable fields. A critical reading of the literature confirms strong links between the hard paradigm and Project Management. However, it is also demonstrated that undercurrents exist in the literature, which suggest a growing acceptance of the soft paradigm. Models of the field are presented through which the influence of these paradigms on the field can be understood, and a way is suggested in which further developments in the use of the soft paradigm in Project Management could be progressed.
\end{abstract}

Keywords: Theoretical basis; Systems approach; Paradigms

\section{Introduction}

Over the last few decades a great deal has been written about the hard and soft paradigms, two broad tendencies for thought which have had a strong influence on the development of a variety of practical and academic disciplines. Previous authors [e.g. 2,8 ]have stated that the development of Project Management (PM) has been strongly influenced by the hard paradigm. However, there has be little in depth examination of the veracity of these claims in the PM literature.

Others claim that the field of PM currently lacks a coherent underlying theoretical basis [e.g. 17, p. 2; 50, p. 5 ], that additional theoretical development is needed, and that the general "...conceptual framework is inadequate to the job it should be addressing" [49, p. 31]. Theory in PM is predominantly implicit. Development of an explicit theoretical basis for PM has been heralded as one of the most crucial issues in the development of the profession [11, p. 293]. It has been suggested "...that a paradigm change, long overdue, has to be realized" [11, p. 298].

The purpose of this paper is to explore whether claims regarding the hard paradigmatic basis of PM can be substantiated based on evidence in the PM literature, and to examine how the hard and soft paradigms have influenced, and are continuing to influence, the field. It is also argued that the field of PM may actually be in the process, not of a paradigm change, but an expansion of paradigms that are acceptable and applied within the field.

This paper contributes to development of an explicit understanding of the theoretical basis of PM. Models of the role of the hard and soft paradigms in the field are presented, and some ways in which this paradigm expansion could be further progressed are suggested.

\section{The hard and soft paradigms}

The term paradigm came into popular usage with Kuhn's (1962) The structure of scientific revolutions [3] and can generally be taken as referring to the commonly shared set of assumptions, values and concepts within a community, which constitutes a way of viewing reality. Individuals within the community may embody 
these assumptions in different ways, and so paradigm is used in this context to refer to a general tendency for thought.

The terms hard and soft are often inconsistently and ambiguously used in the PM literature [4, p. 645]. For instance, the term soft is often used to indicate a vague focus on people or intangibles. However, in the literatures of some comparable fields the terms hard and soft have more complex meanings, referring to two distinct paradigms, each of which involves particular values, ways of viewing the world and approaches to practice.

The hard paradigm is commonly associated with a positivist epistemology, deductive reasoning and quantitative or reductionist techniques, attributes which are often associated with rigour and objectivity. Practice based on the hard paradigm tends to emphasise efficient, expert-led delivery, control against predetermined goals and an interest in underlying structure.

The soft paradigm is commonly associated with an interpretive epistemology, inductive reasoning, and exploratory, qualitative techniques, which emphasise contextual relevance rather than objectivity. Practice based on the soft paradigm emphasises learning, participation, the facilitated exploration of projects, and typically demonstrates an interest in underlying social process. The relationship between these different attributes and how they interact in a PM context is described in Fig. 1 . This figure is a synthesis of the different ways that the hard and soft paradigms have been described in other research [4, p. 650; 76, p. 319; 77, p. 45; 78, p. 290; 79, p. 22].
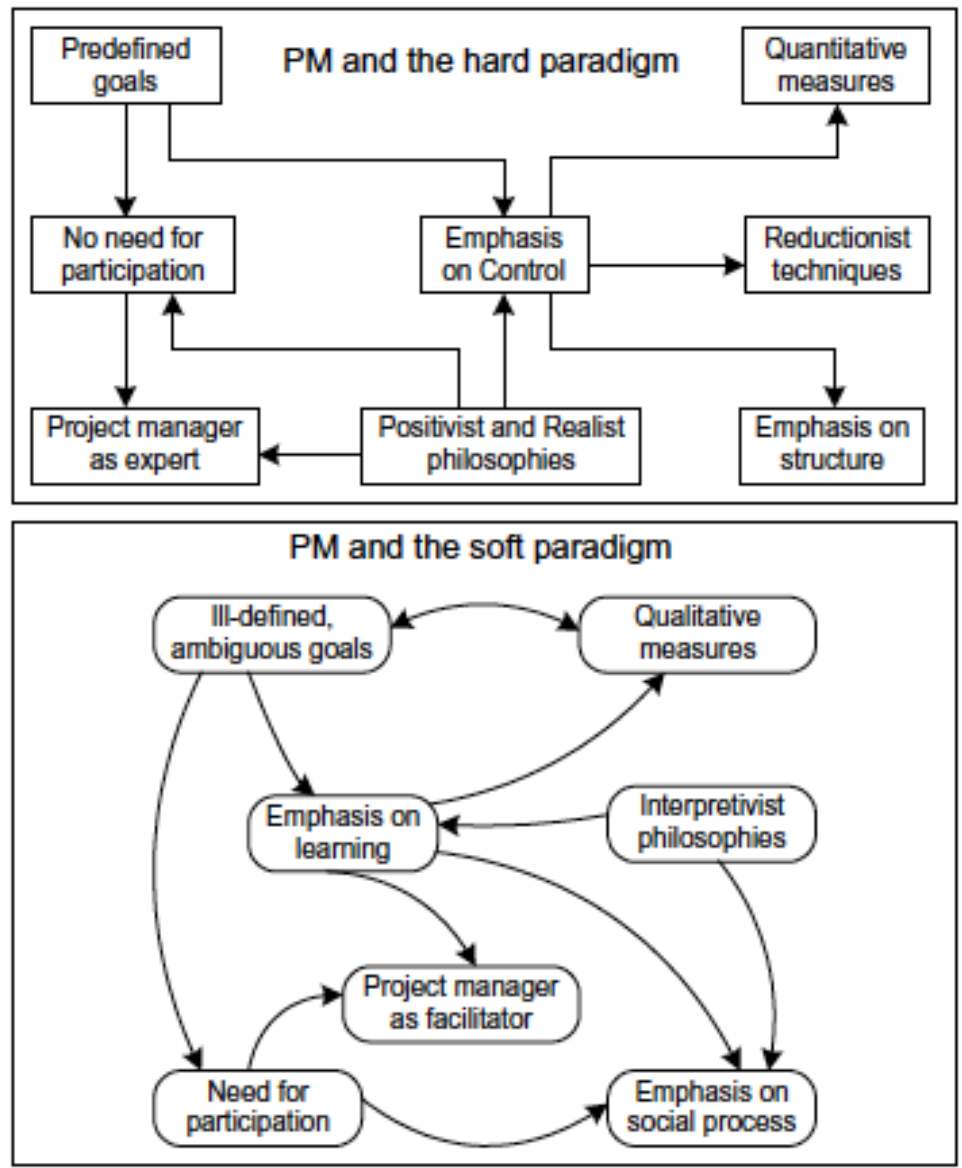

Fig. 1. Interrelationship between the attributes of the hard and soft 
In many cases, these paradigms have been referred to by the philosophies which underpin them. For instance, the hard paradigm has also been referred to as the rationalistic, positivistic, scientific, reductionist [5, p. 26] or quantitative paradigm [6, p. 46]. The soft paradigm has alternatively been referred to as hermeneutic, qualitative, phenomenological, interpretive, reflective, inductive or ethnographic paradigm $[7$, p. 20].

However, the philosophical side is only one aspect of these paradigms. Paradigms influence practice in terms of how situations are perceived, what is considered to be of value, and what is viewed as valid and effective action. The influence of a paradigm on practice can be subtle, but it is pervasive, affecting what is done, how it is done and why it is done.

In the field of Systems Thinking it has been demonstrated that different paradigms and methodologies are appropriate for different contexts and effective in reaching different ends [e.g. 43,44,51,67 ]. In the field of Operational Research practical methodologies based on the hard and soft paradigms are sometimes referred as Problem Solving and Problem Structuring methodologies, respectively [80], names which are suggestive of the different purposes to which these methodologies are put.

The differences between the hard and soft paradigms have varying implications at the levels of theory and practice, and so to understand the influence of these paradigms on PM it is necessary to examine both of these levels (see Fig. 2 ). Although the terms hard and soft are not unproblematic, they are used throughout this study as they do not place particular emphasis at either the philosophical or the practical level. Further examination of the differences between these paradigms can be found in works by Jackson [8] and Midgley [9] who provide analyses of the influence of these paradigms on the fields of Management Science, Systems Thinking and Social Research.

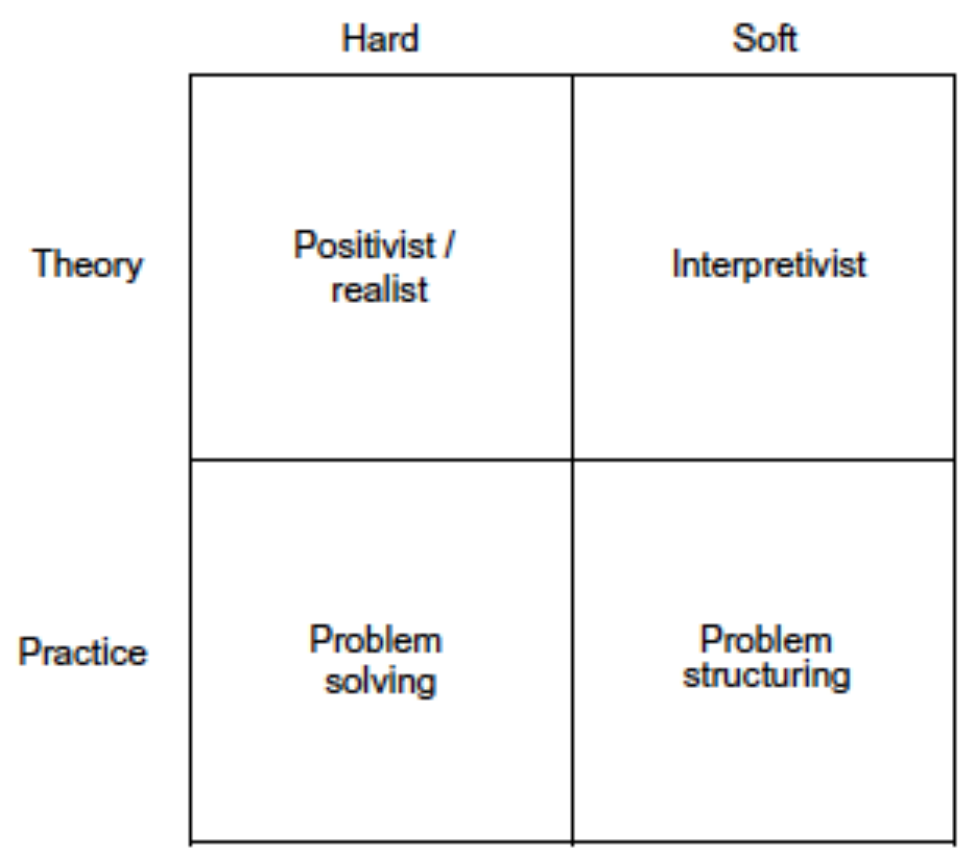

Fig. 2. The hard and soft paradigms in theory and practice 


\section{Methodology}

Previous authors have suggested that through analysis of the work of leading scholars and documentation, it is possible to deduce the theories on which PM is based [11, p. 294]. A similar approach is taken here, with conclusions on the paradigmatic basis of PM being based on a critical reading of the literature.

As a paradigm is a broad tendency in the way the world is perceived by a group, and as individuals within the group may embody these tendencies in different ways, it has been necessary to draw upon fragments from multiple sources in order to piece together a cohesive whole. The views of a single author alone would not constitute an argument regarding the paradigmatic basis of the field. However, when tendencies in the literature are taken together, the paradigmatic basis of the field can become clear.

$P M$ is a diffuse field, with practitioners in many countries, industries and application areas. This paper takes traditional PM as having developed from origins in the defence, engineering, construction and aerospace industries, and to have been strongly influenced by the Project Management Institute and its Guide to the Project Management Body of Knowledge [10].

The 'texts' under focus in this research are a selection of research articles from PM specific publications and conferences. Emphasis has been placed on the academic publications, rather than the trade publications, as discussion at a theoretical level is more likely to be found in these sources. Research has sought indicative sources which can be interpreted as indicating alignment between PM and some of the identifying attributes of the hard or soft paradigms in Fig. 1. The majority of books, conference papers and research papers referred to have been published within the last 15 years.

\section{Philosophical basis of PM}

Examination of the literature reveals that PM has developed as an essentially purposeful, functionalist activity, aligning with the hard paradigm in terms of tendencies towards positivist and realist philosophies, an emphasis on objectivity, and a focus on reductionist techniques and control.

PM effort is coordinated to reach a particular goal or perform some specific function. The field demonstrates "...a means-end paradigm with a strong emphasis on discipline, goal seeking and end-item accomplishment" [1, p. 113]. An emphasis in PM can also be seen on performance measures which focus on objectivity and eschew an acceptance of subjectivity [15, p. 39]. Popular techniques are predominantly those which allow the project manager to "...obtain and use objective data, as opposed to relying on subjective judgement" [16, p. 6].

A focus on objectivity and the assumption of a stable and equally accessible reality can be taken as indicative of a realist philosophical underpinning. Indeed, most PM "...writers seem to imply that some form of empirical realism is possible [17, p. 17]. Further philosophical links to the hard paradigm are apparent in the literature, with the PMBOK® Guide [18, p. 90], and PM as a whole [19, p. 1], having been linked to positivist philosophies. Reductionism has also been identified as a distinguishing characteristic of the hard paradigm. "Another deep-seated influence on project management thinking holds that the nature of complex things can always be reduced or explained by simpler, more fundamental things" [20, p. 3]. It is generally expected that the goals and the required work can be decomposed [11, p. 296]. This 
perspective is apparent in the prevalence of breakdown structures (e.g. WBS) and project definition hierarchies.

A desire for control can also be taken as indicative of the hard paradigm. The idea of control "....is intimately linked with the idea that a stable geometrical model of the universe is not only desirable but also possible" [20, p. 3]. There is a strong trend towards control in the PM literature [32, p. 54]. An assumption that human destiny is controllable pervades the PM profession [33, p. 371], with many PM principles focusing more on creating the idea of control than on learning $[31, p .6]$.

\section{Organisations and project organisation}

The PM literature tends to adopt a perspective on organisation which is mechanistic, focusing on the structure of organisation and its centralised control. The PM perspective often assumes that there is a strong causal connection between the actions of management and organisational outcomes, and that orders are fully understood and executed according to plan [11, p. 6]. There are many different metaphors through which organisations can be described [34]. However, projects and organisations are still commonly viewed as machines [31, p. 2], and it is the machine metaphor which dominates the PM literature.

The PM focus on organisation also emphasises how best to design and control the organisational structure, so as to achieve greatest efficiency for project delivery. Organisations are seen as directed towards achieving some shared and understood goal [16, p. 271]. This organisational model can then be thought of as based on a functionalist perspective, where analysis of organisation is based around a focus on how the organisation achieves particular explicitly defined goals. Goal achievement is assumed to be at the heart of organisation, and analysis of organisation focuses on how best to coordinate organisational functions. A functionalist and mechanistic perspective on organisation in PM also aligns with the hard paradigm.

\section{A hard perspective on people and participation}

Projects are managed by people often in highly stressful situations, significantly unlike those experienced in general management situations. Given this, it would be reasonable to expect that many PM specific approaches to Human Resource Management (HRM) would have been developed. "Astonishingly, this does not seem to be the case: a review of the literature reveals that the application of HRM practices in PM is in fact rather elementary" [38, p. 86]. Instead, the PMBOK® Guide [10, p. 107] simply refers the project manager to the extensive external HRM literature.

Furthermore, the "...traditional thinking behind a project risk management (PRM) framework is essentially centrist, authoritarian. It... assumes that the central project manager knows 'best"' [40, p. 221]. Williams [40, p. 219] suggests that in PM, participation and empowerment may actually increase risk by reducing centralised control. A low emphasis on interpersonal matters and participation, and a strong emphasis on a centralised, expert-based perspective aligns with the hard paradigm.

\section{The definition and stability of goals}

At a practical level, PM tends to adopt a problem solving, rather than a problem structuring, approach to projects. Further structuring of the situation tends to be assumed to be unnecessary or outside the scope of PM. The PM literature tends to assume the existence of a pre-existing business plan, with clearly defined goals and constraints [29, p. 42], clear customer requirements, and goals that can be 
decomposed [11, p. 296]. The literature recommends that where uncertainty exists, it should be reduced in favour of certainty, clarity and distinctness [e.g. 30, p. 101 ]. Uncertainty is then reframed "...in an unambiguous and familiar way; consequently ambiguity is transformed to distinctness and the unknown to the known" [31, p. 2].

Goal clarity has widely been associated with project success $[21$, p. $6 ; 22$, p. $72 ; 23$, p. 29; 24, p. 52]. The level of goal definition [21, p. $6 ; 25$, p. 55], how well goals are understood [26, p. 6], the efficiency of project planning [24, p. 52], the way goals are established [27, p. 156], and achievement of early and explicit agreement as to how goals will be measured [28, p. 71$]$ are also traditionally considered to be key project success factors.

Methodologies developed under the hard paradigm consistently assume clear and stable goals. Theoretically, goals are expected to remain stable, and members of a project are not expected to introduce changes to goals. Goal change is avoided and goals only tend to be changed when a significant stakeholder, such as a customer, requires it. Even then, goal change is made reluctantly [31, p. 5]. These tendencies for assumptions regarding goals indicate that PM is traditionally used for problem solving, rather than problem structuring.

\section{A hard interpretation of PM tools and techniques}

A strong emphasis on the hard paradigm can also be seen in how the tools and techniques commonly associated with PM have developed. PM tools and techniques are predominantly quantitative. For instance, Söderlund [14, p. 21] identifies “...that 'traditional' project management research is classifiable either as one of 'optimization' or as 'critical success factor' research..." where the former primarily involves reductionist breakdown techniques, and the latter favors quantitative analysis of large surveys. The majority of PM techniques have been developed in such a way as to require prerequisites of specified objectives, actions to complete objectives that can be determined in advance, and a desired sequence for performing the activities [16, p. 387]. The appropriateness of some of these basic assumptions is coming into question in many project contexts.

The classical PM techniques are starting to be seen as appropriate only in the simplest problem contexts [62, p. 80], are being recognised as inadequate for complex projects [21, p. 9] and seen as unable to address the stochastic nature of project $[63$, p. 96]. These kinds of criticisms have been raised in relation to some of the techniques most commonly associated with traditional PM, such as: breakdown structures [48, p. 2; 64, p. 39]; network analysis in general [20, p. 7]; PERT [48, p. 2; 52 , p. 279-81]; and critical path analysis [65, p. 138].

It is interesting that so many different researchers have pointed out the limitations of the assumptions on which these tools and techniques have been based. Although these references can be taken as indicating a traditional emphasis on the hard paradigm in PM tools and techniques, the variety of researchers identifying the consequences of this emphasis can also be taken as indicating a movement away from the traditional way these tools and techniques are applied.

\section{The influence of other fields}

In the field of Systems Thinking there are distinct traditions referred to as hard and soft systems thinking [8]. Of these two traditions, PM research has been biased towards "...the hard systems approach, and it has heavily emphasised quantitative techniques in project planning, scheduling and control" [1, p. 115]. PM has been 
influenced by systems methodologies such as Systems Analysis, Systems Engineering [1, p. 111; 36, p. 13] and Cybernetics [42, p. 33], methodologies which explicitly draw upon the hard paradigm.

Similarities are also apparent between the development of PM and developments within Operational Research, a field which is closely related to Systems Thinking. In discussing the traditional techniques associated with Operational Research, Pidd [46, p. 7] comments that they are very effective in situations typified by common situational logic, but less useful in 'messy' situations. These observations also apply to the traditional tools and techniques of PM, as discussed above.

Strong links between PM and the hard paradigm are apparent at both the levels of theory and practice. These links can be seen in relation to: the influence of hard systems thinking; a philosophical basis in positivism and realism; an assumption that goals are simple, stable and are often defined before the project commences; an emphasis on control to predetermined plans and goals; a structure based view of organisation; and an emphasis on centralised control instead of participation.

\section{Theoretical disquiet and undercurrents of the soft paradigm}

The paradigmatic basis of traditional of PM is “...becoming increasingly questioned in practice in terms of its underlying theories and principles and its breadth and nature of application" [47, p. 207]. A positivist philosophical basis has been found not to have increased levels of control and predictability [18, p. 90]. Instead, a focus on control has been found to restrict PM "...to managing relatively simple projects in relatively stable environments" $[31$, p. 6]. Similarly, reductionist approaches, such as decomposition, have been found to be inadequate for addressing systemic effects [48, p. 3], while the general conceptual basis of PM has been questioned in terms of its ability to address complex problems [19, p. 1].

The important point to be taken from this is that the traditional assumptions of PM are suited to specific contexts; those where efficiency and control are paramount, and where goals are predetermined, uncontested, and are expected to remain that way. However, appropriateness in one context does not mean appropriateness in all. PM is now being applied to non-traditional areas, such as organisational change and information systems development, where change may be common, and the negotiation of goals may be as important to success as efficiency of product delivery. Being explicit about the assumptions which underpin action is key in addressing the demands of different practice environments.

Explicit recognition of an alternative to the hard paradigm as a potential basis for PM is growing. For instance, Hassen [52, p. 285] notes the need for a different approach to management in soft project environments. It has been identified that there has been a recent broadening of PM research [13, p. 655]. For instance, Remington and Crawford [20, p. 11] note that soft and critical systems thinking are both being tested in complex project environments. Examples of PM research using methodologies associated with the soft paradigm are also starting to appear in the literature [e.g. $17,33,53-55,12$, p. 185 ], while the existence of a branch of sociological PM research has been identified, distinct from more traditional research based in engineering and applied mathematics [12, p. 185].

Some writers have identified that understanding the differences between hard and soft PM can influence project success [e.g. [1,56-60]]. Classifications of the differences between the hard and soft paradigms are also starting to appear in the PM literature, including general classification schemes [4], those based on project 
output tangibility [56], and also on the degree of definition of project goals and objectives [61].

\section{A soft perspective on people and participation}

At a practical level, some of the assumptions which underpinned traditional understandings of the role of the project manager are being re-evaluated. For instance, traditionally project managers assume the role of expert instead of facilitator, expecting people to follow orders rather than encouraging participation. However, a growing body of research is suggesting that this approach is not appropriate to all situations, with some authors [e.g. 39, p. 500 ]linking low levels of participation to project failure.

An increasing body of data from research suggests that many project success factors centre on human relationships [26, p. 3], that many developmental problems are grounded at the cultural level [35, p. 14], and that projects often lack good communication with stakeholders outside the project team [36, p. 387]. Yeo [37, p. 243] identifies "...technology focus over human relations..." and "...technical fix for a management problem..." as key factors that influence failure. Similarly, Posner [24, p. 52] has found that less that $1 \%$ of project managers surveyed mentioned technical difficulties as the cause of problems in their projects, which "...underscores the claim that the primary problems of project managers are not technical, but human" [24, p. 54].

\section{Reinterpreting goal definition}

In some contexts project goals are neither adequately defined at the start of the project nor stable throughout the life of the project. Application areas such as cultural organisational change projects generally have to rely on goals which are only abstractly defined [28, p. 53]. In many cases, project goals have the habit of changing, even "...after the requirements have apparently been finalised" [68, p. 8]. However, problem solving approaches based in the hard paradigm do not generally address goal definition and situations with a lack of firm definition may be essentially unmanageable because of this.

When project goals are poorly defined, Morris [41, p. 14]suggests using an approach such as Soft Systems Methodology [69], a traditional problem structuring methodology, to define goals before a traditional PM approach is used. This tactic may be appropriate in situations where there is initial ambiguity. However, danger may exist in the early simplification of goals, as this can foreclose on options that should, at the time, be kept open [62, p. 80].

Many authors [e.g. 68, p. 8; 70, p. 20 ]note the possibility for substantial change to goals throughout the life of a project, where a satisfactory definition of project goals “...may need several iterations to unravel" [71, p. 9]. In some situations extra attention to goal definition at the start of a project may not be sufficient to ensure goal clarity throughout the project. Instead, it may be necessary to reinterpret the whole project process in terms of problem structuring, continually reviewing and redefining goals throughout the project, instead of assuming that goals, once defined, will remain stable. Inquiry in the literature into different ways in which problem structuring approaches can be incorporated into the process of PM indicates some penetration of the soft paradigm at a practical level.

\section{Rethinking project planning and control}


Implicit in the hard paradigm is the assumption that a more detailed plan allows for tighter control, and is therefore better. However, a preoccupation with planning has been linked to project failure [37, p. 243]. Highly detailed or rigid plans have been identified as limiting freedom to make decisions [39, p. 499] and encouraging an attitude where low level products become ends in themselves, instead of contributing to a greater goal $[28$, p. 154]. Traditional PM planning approaches tend to be reductionist. However, an overly reductionist approach can lead to a situation where subsystems are optimised at the cost of the project as a whole [72, p. 341]. Some authors [e.g. 66, p. 89 ]argue for a less reductionist approach to project planning, where activities are planned as the project progresses, and the results of previous actions are known.

Empirical evidence suggests that it is impossible to maintain a complete and up to date plan [11, p. 297]. In many project environments, change is common or even constant, for example bureaucratic environments [52, p. 281] and organisational strategy development projects [73, p. 46]. Change can even occur as an unsolicited result of project work [28, p. 49]. As a result of unpredictable change, Turner [28, p. 5]notes that the one thing that you can guarantee about a plan is that it will be wrong, and that one must be willing and ready to change the plan as the project progresses.

In many complex projects, it is impossible to foresee the actions which will be needed in the future. In these situations, holding to an educated guess may be more costly than admitting that the situation is uncertain and that it is too early to make a decision. The consequence of this is that there may then be no definite measures to control against. Through consultation and facilitation, the project manager then has to define as they go, adapting as the project unfolds. This is an approach to planning which is common in problem structuring methodologies.

\section{Continuous definition and evaluation}

An "...emerging discomfort with notions of control through pre-determined outcomes..." has been found in the PM literature [20, p. 2]. An alternative perspective to the traditional one is that change and the inherent uncertainty of some projects must be embraced, "...rather than linearised and ignored..." [74, p. 3]. Indeed, in response to regular change, many project teams spend more time defining and redefining their projects than on controlling or planning them [33, p. 378]. Definition and evaluation can become continuous processes.

A shaping approach, instead of one based on planning and control, may be more appropriate for complex environments [29, p. 43]. In response to change, project managers must continuously review the time, cost and quality aspects of the project $[75$, p. 31] and redefine the project scope and definition of their mandate [33, p. 378]. Therefore, plans need to be flexible enough to allow for the incorporation of new ideas, new developments and changes in direction [73, p. 52]. There is clearly a growing appreciation in the literature that for projects "...that are complex, uncertain, and time-limited, conventional methods might be inappropriate, and aspects of newer methodologies in which the project 'emerges' rather than being fully pre-planned might be more appropriate"' [82, p. 497].

Redefinition of scope and goals requires learning on the part of stakeholders and the project team. Yeo [1, p. 116] identifies that the secret of success in PM is learning, and that this is especially true in ill structured or ambiguous situations. Problem structuring approaches tend to focus on facilitated participative learning. Involving stakeholders in the goal definition and planning processes can encourage shared learning regarding both what the client needs and what the project team is capable of 
in the present context.

\section{Rethinking PM tools and techniques}

Tools and techniques are appearing which may be more appropriate for planning in complex, dynamic or uncertain environments, such as milestone planning. For instance, in situations where only broad goals may be scheduled and defined, milestone planning can still be used effectively [30], providing the benefit of demonstrating precedence without the need for detailed plans [66].

However, there are few PM specific tools and techniques which emphasise problem structuring. If project managers are to meet the needs of situations which require a greater emphasis on problem structuring, rather than problem solving, then further development is needed. A way forward is to reinterpret existing tools and techniques in light of a different paradigm.

PM tools and techniques are regularly being refined and improved. For example, Williams [81] demonstrates how Monte Carlo simulations do not take account of some aspects of complex project behaviour and offers suggestions on how this technique could be refined to provide more accurate simulations. However, the refinements suggested are quantitative and offered as a way of increasing accuracy of estimation, an intention which suggests a realist perspective. In this example, improvements to the technique seem to remain within the hard paradigm.

It is important to realise that tools and techniques are independent of the purposes for which a practitioner may choose to apply them. In relation to the bottom half of Fig. 2 , problem solving and problem structuring are two purposes to which tools can be used. Tools which are typically associated with one paradigm can move across to the other side of this figure. A tool which has traditionally been a been used as a problem solving tool can be used for problem structuring if it is thought about and applied in a different way.

Interpreting tools and techniques in light of the soft paradigms entails adopting a significantly different perspective, and involves substantially more than utilising a new set of linguistic tools [83, p. 205]. It requires that the practitioner becomes bodily involved in the paradigm through experience and practice [84, p. 501], a process which "...may be said to require both a learning and an un learning" [83, p. 209].

To do this we need to understand tools and techniques differently. Looking back at Fig. 1 , a first step might be to acknowledge the ambiguity in the situation, that goals may only be qualitative and ill-defined, and that it may not be possible to create clarity in the short term. The next step would be to examine how a particular tool or technique could be used to engage stakeholders, and to facilitate and structure debate.

Some emphasis in the use of the tool almost necessarily has to come off reductionism, quantification and estimation. The purpose in using the tool or technique would be to help people learn each others' perspectives on the situation and to come to an accommodated position about possible actions that could be taken. The emphasis would change to understanding the social process in the situation, and overcoming any obstacles preventing stakeholders reaching the agreement necessary to initiate project work.

\section{Conclusions}


The theoretical basis of PM is predominantly implicit, and discussion of the theoretical basis of PM is rare. If the field is to progress, explicit understanding of the theoretical basis of PM is necessary, as it provides the opportunity to understand the assumptions which underpin practice, to question their appropriateness, and then consciously choose an alternative, when it is appropriate to do so.

Examination of the literature shows many examples to indicate that traditional PM is deeply rooted in the hard paradigm. This is apparent in significant assumptions and attitudes regarding the purpose of PM, the contexts it is suited to, and the role that project managers are traditionally expected to play. By contrast, the influence of the soft paradigm on PM is less substantial, but it does appear that respect for this paradigm is growing within the field. Evidence of its influence is often in the form of authors identifying existing deficiencies or questioning existing assumptions, rather than embodying the assumptions of the soft paradigm in research or practice.

The range of theoretical frameworks being applied in PM research and practice appears to be expanding, and the field "...shows a significant level of plurality" [14, $p$. 20]. Evidence for the influence of both the hard and soft paradigms on PM supports this. Increasing diversity of theoretical frameworks in the field of Information Systems has been heralded as "...as a healthy sign for research progress..." [45, p. 561] and a "...sign of maturation of a discipline..." [45, p. 559]. An increase in theoretical diversity can be taken as a health sign for the field of PM as well.

A paradigmatic expansion provides increased opportunity for practitioners and researchers. What is visible, valuable, or considered relevant from any one paradigm is both dependant upon and limited by, the assumptions which underpin it. No one perspective is appropriate to all situations. For project managers in non-traditional application areas, it is necessary to be able to adapt the approach taken to suit the current demands. A wider variety of paradigms employed within the field increases the ways in which existing techniques are understood, allowing familiar techniques to be applied to new situations in novel ways.

\section{Acknowledgement}

This is an extended version of a paper that won the PM Days Student Paper Award, 2005, Vienna, Austria.

\section{References}

[1] Yeo KT. Systems thinking and project management - time to reunite. Int J Proj Manage 1993;11:111-7.

[2] Winter M, Checkland P. Soft systems: a fresh perspective for project management. Civil Eng - Proc ICE 2003;156:187-92.

[3] Kuhn T. The structure of scientific revolutions. Chicago: University of Chicago Press; 1962.

[4] Crawford L, Pollack J. Hard and soft projects: a framework for analysis. Int J Proj Manage 2004;22:645-53.

[5] Oakley P. How the name date (Harvard) reference style in papers shows an underlying interpretivist paradigm whilst numeric references show a functional paradigm? Systemist 2003;25(1):25-30.

[6] Higgs J. Charting standpoints in qualitative research. In: Byrne-Armstrong $\mathrm{H}$, Higgs J, Horsfall D, editors. Critical moments in qualitative research. Oxford: Butterworth-Heinmann; 2001. p. 45-67.

[7] Ticehurst GW, Veal AJ. Business research methods. Malaysia: Pearson Education Australia; 2000. 
[8] Jackson MC. Systems approaches to management. New York: Plenum Press; 2000.

[9] Midgley G. Systemic intervention: philosophy, methodology, and practice. New York: Plenum Press; 2000.

[10] PMI. A guide to the project management body of knowledge, 2nd ed. (PMBOK_ Guide). PA, USA: Project Management Institute; 2000.

[11] Koskela L, Howell G. The underlying theory of project management is obsolete. In: Proceedings of PMI research conference; 2002. p. 293- 301.

[12] Söderlund J. Building theories of project management: past research, questions for the future. Int J Proj Manage 2004;22:183-91.

[13] Söderlund J. On the broadening scope of the research on projects: a review and a model for analysis. Int J Proj Manage 2004;22:655-67.

[14] Söderlund J. On the development of project management research: schools of thought and critique. Int Proj Manage J 2002;8:20-31.

[15] Leandri SJ. Measures that matter: how to fine-tune your performance measures? J Qual Participat 2001;24:39-41.

[16] Cleland D, King W. Systems analysis and project management. New York: McGraw-Hill; 1968.

[17] Cooke-Davies T. Towards improved project management practice. Unpublished Ph.D. Thesis, Leeds Metropolitan University; 2000.

[18] Nissen ME, Snider KF. Lessons learned to guide project management theory and research: pragmatism and knowledge flow. In: Proceedings of PMI research conference; 2002. p. 89-98.

[19] Bredillet C. Beyond the positivist mirror: towards a project management 'Gnosis'. In: IRNOP VI conference, Turku, Finland; 2004.

[20] Remington K, Crawford L. Illusions of control: philosophical foundations for project management. In: IRNOP VI conference, Turku, Finland; 2004.

[21] White $D$, Fortune J. Current practice in project management - an empirical study. Int J Proj Manage 2002;20:1-11.

[22] Pinto JK, Slevin DP. Critical success factors across the project life cycle. Proj Manage J 1988;19(2):68-75.

[23] Blockmar I. ONE objective for a successful project! J Aust Inst Proj Manage 2004;24(2):29.

[24] Posner B. What it takes to be a good project manager? Proj Manage J 1987;18(1):51-4.

[25] Dumont P, Gibson E, Fish J. Scope management using project definition rating index. J Manage Eng 1997;13(5):54-60.

[26] Couillard J. The role of project risk in determining project management approach. Proj Manage J 1995;26(4):3-15.

[27] Morris P, Patel MB, Wearne SH. Research into revising the APM project management body of knowledge. Int J Proj Manage 2000;18:155-64.

[28] Turner JR. The handbook of project-based management. London: McGraw-Hill; 1999.

[29] Hobbs B, Miller R. The strategic front end of large infrastructure projects: a process of nesting governance. In: PMI Research conference, Seattle, USA; 2002.

[30] Turner JR, Cochrane RA. Goals-and-methods matrix: coping with projects with ill defined goals and/or methods of achieving them. Int J Proj Manage 1993;11:93-101. [31] Thomas JL, Tjader J. On learning and control - competing paradigms or coexisting requirements for managing projects in ambiguous situations? In: Fourth biannual conference of the international research network on managing by projects, Sydney, Australia; 2000.

[32] Kloppenborg TJ, Opfer WA. Forty years of project management research: trends, interpretations, and predictions. In: Proceedings of PMI research conference; 2000. p. 41-59.

[33] Melgrati A, Damiani M. Rethinking the project management framework: new 
epistemology, new insights. In: Proceedings of PMI research conference; 2002. p. 371-80.

[34] Morgan G. Images of organization. London: Sage Publications; 1997.

[35] Butterfield J, Pendegraft N. Cultural analysis in IS planning \& management. J Syst Manage 1996;47(2):14-7.

[36] Muller R, Turner JR. Communication between IT project manager and project sponsor in a buyer-seller relationship. In: PMI research conference, Seattle, USA; 2002.

[37] Yeo KT. Critical failure factors in information system projects. Int J Proj Manage 2002;20:241-6.

[38] Fabi B, Pettersen N. Human resource management practices in project management. Int J Proj Manage 1992;10(2):81-8.

[39] Hall M, Holt R, Purchase D. Project sponsors under new public management: lessons from the frontline. Int J Proj Manage 2003;21:495-502.

[40] Williams T. Empowerment vs. risk management? Int J Proj Manage 1997;15:219-22.

[41] Morris P. Science, objective knowledge, and the theory of project management. ICE James Forrest Lecture. Available from:

http://www.bartlett.ucl.ac.uk/research/management/lCEpaperFinal.pdf; 2004.

[42] Urli B, Urli D. Project management in North America, stability of the concepts. Proj Manage J 2000;31:33-43.

[43] Jackson M, Keys P. Towards a system of systems methodologies. J Oper Res Soc 1984;35:473-86.

[44] Flood R, Jackson M. Creative problem solving: total systems intervention. New York: Wiley; 1991.

[45] Lee Y, Lee Z, Gosain S. The evolving intellectual diversity of the IS discipline: evidence from referent theoretical frameworks. Commun Assoc Information Syst 2004;13:546-79.

[46] Pidd M. Complementarity in systems modelling. In: Pidd M, editor. Systems modelling: theory and practice. Chichester: Wiley; 2004. p. 1-20.

[47] Betts M, Lansley P. International Journal of Project Management: a review of the first ten years. Int J Proj Manage 1995;13:207-17.

[48] Rodrigues AG, Williams TM. System dynamics in project management:

assessing the impact of client behavior on project performance. J Oper Res Soc 1998;49:2-15.

[49] Morris P. Research trends in the 1990s: the need now to focus on the business benefit of project management. In: Slevin D, Cleland D, Pinto J, editors. The frontiers of project management research. Pennsylvania, USA: Project Management Institute; 2002. p. 31-56.

[50] Shenhar AJ. Project management theory: the road to better practice. In: Project management institute 27th annual symposium; 1996. p. 1-6.

[51] Mingers J. A classification of the philosophical assumptions of management science methods. J Oper Res Soc 2003;54:559-70.

[52] Hassen NB. Soft project methodologies - using mind mapping, and scenario/future mapping techniques in business and public sector projects to develop effective project plans. In: AIPM national conference proceedings; 1997. p. 276-86. [53] Friend J, Bryant D, Cunningham B, Luckman J. Negotiated project management: learning from experience. Hum Relat 1998;5(12): 1509-11.

[54] Costello K, Crawford L, Bentley L, Pollack J. Connecting soft systems thinking with project management practice: an organizational change case study. In: Ragsdell $G$ et al., editors. Systems theory and practice in the knowledge age. New York:

Kluwer Academic/Plenum Press; 2002.

[55] Crawford L, Costello K, Pollack J, Bentley L. Managing soft change projects in the public sector. Int J Proj Manage 2003;21:443-8.

[56] McEIroy W. Implementing strategic change through projects. Int J Proj Manage 
1996;14:325-9.

[57] Wateridge $\mathrm{J}$. The role of configuration management in the development and management of information systems/technology (IS/IT) projects. Int J Proj Manage 1999;17(4):237-41.

[58] Williams T. The need for new paradigms for complex projects. Int J Proj Manage 1999;17:269-73.

[59] Williams T, Hillson D. PMI Europe 2001 - editorial. Int J Proj Manage 2002;20(3):183-4.

[60] Jaafari A. Management of risks, uncertainties and opportunities on projects: time for a fundamental shift. Int J Proj Manage 2001;19:89-101.

[61] Stretton A. An investigation of connections between organizational change and project management. In: IRNOP IV conference, Sydney, Australia; 2000.

[62] Daniel D. Hard problems in a soft world. Int J Proj Manage 1990;8(2):79-83.

[63] Starr MK. The role of project management in a fast response organization. J Eng Technol Manage 1990;7:89-110.

[64] Luby R, Peel D, Swahl W. Component-based work breakdown structure (CBWBS). Proj Manage J 1995;26(4):38-43.

[65] Vickers G. Value systems and social process. Middlesex, England: Pelican Books; 1968.

[66] Andersen E. Warning: activity planning is hazardous to your project's health! Int J Proj Manage 1996;14(2):89-94.

[67] Flood R, Romm N. From MetaTheory to "Multimethodology". In: Mingers J, Gill A, editors. Multimethodology: the theory and practice of combining management science methodologies. Chichester: Wiley; 1997. p. 291-322.

[68]Neal RA. Project definition: the soft-systems approach. Int J Proj Manage 1995;13:5-9.

[69] Checkland P. Soft systems methodology: a 30-year retrospective. In: Checkland $P$, Scholes J, editors. Soft systems methodology in action. Chichester: Wiley; 1999.

p. A1-A65.

[70] Remenyi D, Sherwood-Smith M. Maximise information systems value by continuous participative evaluation. Logist Information Manage 1999;12:14-31.

[71] Bentley L. Realising the benefits from public sector projects. J Aust Inst Proj Manage 2004;24(2):9-11.

[72] Liu A, Leung M. Developing a soft value management model. Int J Proj Manage 2002;20:341-9.

[73] Kenny J. Effective project management for strategic innovation and change in an organizational context. Proj Manage J 2003;34(1):43-53.

[74] Richardson K, Tait A, Lissack M. The potential of group decision support tools in the coherent management of complex projects. In: IRNOP IV conference, Sydney, Australia; 2000.

[75] Baccarini D. Project life cycle - helping to understand project management. J Aust Inst Proj Manage 2004;24(4):31.

[76] Fitzgerald B, Howcroft D. Towards dissolution of the IS research debate: from polarization to polarity. J Information Technol 1998;13:313-26.

[77] Spencer L, Ritchie J, Lewis J, Dillon L. Quality in qualitative evaluation: a framework for assessing research evidence. UK Cabinet Office: Government Chief Social Researcher's Office. Available from:

http://www.strategy.gov.uk/files/pdf/Quality_framework.pdf; 2003.

[78] Checkland P. From optimizing to learning: a development of systems thinking for the 1990s. Midgley G, editor. Systems thinking, vol. III. London: Sage Publications; 2003.

[79] Burrell G, Morgan G. Sociological paradigms and organizational analysis. Aldershot, England: Gower Publishing; 1979.

[80] Wooley R, Pidd M. Problem structuring - a literature review. J Oper Res Soc 1981;32(3):197-206. 
Cite as: Pollack, J. (2007) The changing paradigms of project management. International Journal of Project Management, 25, 266-274, doi:10.1016/j.ijproman.2006.08.002

[81] Williams T. Why Monte Carlo simulations of project networks can mislead? Proj Manage J 2004;35(3):53-61.

[82] Williams T. Assessing and moving on from the dominant project management discourse in the light of project overruns. IEEE Trans Eng Manage 2005;52(4):497. [83] Brocklesby J. Becoming multimethodology literate: an assessment of the cognitive difficulties of working across paradigms. In: Mingers J, Gill A, editors. Multimethodology: the theory and practice of combining management science methodologies. Chichester: Wiley; 1997. p. 189-216.

[84] Mingers J, Brocklesby J. Multimethodology: towards a framework for mixing methodologies. Omega-Int J Manage Sci 1997;25: 489-509. 